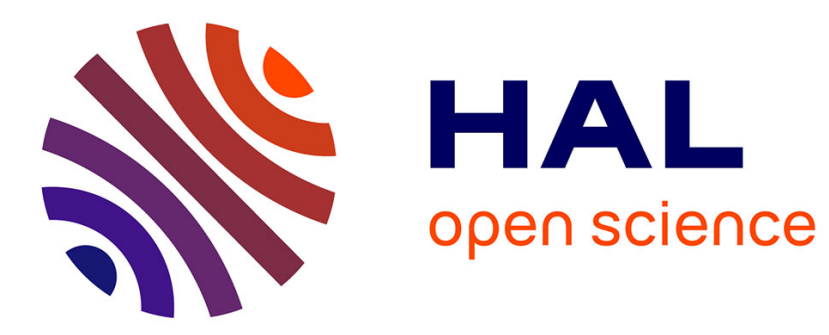

\title{
Hormonal therapy and depression: are we overlooking an important therapeutic alternative?
}

\author{
Marie-Laure Ancelin, Jacqueline Scali, Karen A. Ritchie
}

\section{To cite this version:}

Marie-Laure Ancelin, Jacqueline Scali, Karen A. Ritchie. Hormonal therapy and depression: are we overlooking an important therapeutic alternative?: Hormonal therapy and depression. Journal of Psychosomatic Research, 2007, 62 (4), pp.473-85. 10.1016/j.jpsychores.2006.12.019 . inserm00138466

\section{HAL Id: inserm-00138466 https://www.hal.inserm.fr/inserm-00138466}

Submitted on 1 Oct 2007

HAL is a multi-disciplinary open access archive for the deposit and dissemination of scientific research documents, whether they are published or not. The documents may come from teaching and research institutions in France or abroad, or from public or private research centers.
L'archive ouverte pluridisciplinaire HAL, est destinée au dépôt et à la diffusion de documents scientifiques de niveau recherche, publiés ou non, émanant des établissements d'enseignement et de recherche français ou étrangers, des laboratoires publics ou privés. 


\section{HORMONAL THERAPY AND DEPRESSION: ARE WE OVERLOOKING AN IMPORTANT THERAPEUTIC ALTERNATIVE?}

Running Title: Hormonal therapy and depression

Marie-Laure ANCELIN*, Jacqueline SCALI and Karen RITCHIE.

Inserm, U888, Montpellier, F-34093 France ; Univ Montpellier1, Montpellier, F-34000, France.

*corresponding author:

Marie-Laure Ancelin

Inserm U888, Epidemiology and Clinical Research in Nervous System Pathologies, Hôpital La Colombière, Pavillon 42, 39 avenue C. Flahault, BP 34493, 34093 Montpellier Cedex 5, France.

Tel: 334996145 62;

Fax: 334996145 79;

Mail: ancelin@montp.inserm.fr 


\section{ABSTRACT}

Objective: To examine evidence for the role of hormonal changes in the onset and course of depressive symptomatology and assess the possible future role of hormonal therapies in the treatment of depression.

Methods: A Medline and PsychINFO search of the literature published between 1965 and 2006 was made of studies of depressive symptoms and hormonal treatment in women at all stages of reproductive life.

Results: The cyclic fluctuation of gonadal steroids at menarche coincides with the beginning of gender-based differences in depression rates which continue throughout reproductive life until menopause. Modifications in hormonal status, whether related to endogenous or exogenous exposure or to hormone deprivation, appear to be associated with affective disorder in a subgroup of women. For these women, a growing body of evidence indicates a biological pattern of vulnerability to mood disorders in response to hormonal fluctuations. This could have three major implications: that women vary in vulnerability to mood disorder when abrupt change in steroid levels occur, that these effects could be cumulative across the female lifespan, and that women do not arrive at menopause with equal risk of mood disorders, or equal susceptibility to the effects of hormonal replacement therapy as has been assumed by current clinical research and practice.

Conclusion: While hormonal therapies could have positive effects in the treatment and prevention of depressive disorders, further research is required to differentiate hormone-responsive subgroups of women for whom specific hormonal treatments may be most beneficial. To this end we suggest that a multifactorial model of cumulative vulnerability, which takes into account hormonal exposure throughout life, genetic vulnerability and environmental factors, may provide better prediction of treatment response. 
Key words: Biological vulnerability; cumulated lifelong exposure to steroids; depression; estrogens; female reproductive cycle; hormone therapy.

\author{
Abbreviations: \\ CEE: conjugated equine estrogens \\ CES-D: Center for Epidemiologic Studies-Depression \\ DES: diethylstilbestrol \\ ET: estrogen therapy \\ GnRH: gonadotropin releasing hormone \\ HERS: heart and estrogen/progestin replacement study \\ HT: hormone therapy \\ MPA: medroxyprogesterone acetate \\ MRD: menstrually related disorders \\ OC: oral contraceptive
}

PMDD: premenstrual dysphoric disorder

PMS: premenstrual syndrome

PPD: postpartum depression

RCT: randomized controlled trial

SSRI: selective serotonin reuptake inhibitor

SERM: selective estrogen receptor modulator

WHI: women’s health initiative 


\section{INTRODUCTION}

Numerous epidemiological studies have reported that mood disorders are more common in women [1-4]. While gender differences may in part be attributed to factors such as willingness to declare symptoms, hormonal factors are nonetheless believed to play an important role throughout life in relation to mental health. Given that estrogen receptors (ERs) are extensively present in the brain, and that estrogens appear to exert protective effects on neurotransmitter systems (see Refs. [5,6] for reviews), the question currently being raised is whether hormonal therapy (HT) may play a role in the management of psychiatric disorder. Studies of HT have focused principally on the reduction of menopausal symptoms and cognitive dysfunction, and little attention has been paid to psychiatric disorder although improvement in depressive symptomatology is one of the clinical reasons given by many women for maintaining HT. We examine current research on the impact of hormonal functioning on mental health throughout the life cycle, including endogenous endocrine fluctuations (e.g. menstrual cycle, pregnancy, peri-menopause), hormone deprivation (by castration or antihormone treatment), and exogenous endocrine exposure (e.g. oral contraceptives (OCs) or HT) with a view to examining the potential value of hormonal treatment of mood disorders in women.

\section{EFFECTS OF ENDOGENOUS ENDOCRINE FLUCTUATION}

Reproductive-cycle-related mood disorders share some common symptoms, whether they be observed before menstruation (menstrually related disorders MRDs), after childbirth (postpartum depression PPD; postpartum psychosis) or during the perimenopausal transition (see Refs. [7,8] for recent reviews). These disorders include mood instability, changes in sleep and appetite, fatigue, irritability, anxiety, and concentration difficulties. Symptoms specific to a given reproductive phase are also reported, for example, somatic symptoms (breast tenderness, bloating, headaches), food cravings, anger associated with MRD, profound social isolation and obsessive ruminations with PPD, and tearfulness occurring with MRD and perimenopausal depression, the latter being also associated with excessive worry or somatic complaints, such as vasomotor symptoms [7-10]. With regard to MRD, several terms have been used not only as a function of the severity but also as part 
of DSM classification. Premenstrual syndrome (PMS) was first described. In 1987, the DSM-IIIR included criteria for late luteal phase dysphoric disorder (LLPDD), which was changed to premenstrual dysphoric disorder (PMDD) in DSM-IV (with an additional item compared to LLPD), but PMDD was described as an example of depressive disorder that was not otherwise specified. PMDD was considered as a distinct clinical entity in 1999. PMDD may be distinguished from PMS by symptom severity, predominance of mood symptoms, and dysfunction in interpersonal relationships [11]. Throughout the article we will now refer to MRD as recently suggested [12].

\section{Menstruation}

The menarche heralds the beginning of gender-based differences in depression rates which continue throughout reproductive life, decreasing only after the menopause [2,13]. MRD are frequent, occurring in approximately $80 \%$ of women, with $3-9 \%$ in the most severe form, PMDD. They are characterized by recurrent physical and emotional symptoms that generally occur during the late luteal phase of the menstrual cycle (when ovarian hormone levels decrease progressively to the minimal levels observed at the onset of the menarche) and remit within a few days after menstruation (see Ref. [14] for review). During the premenstrual and menstrual phases women are observed to be at increased risk for both onset of a new depressive episode and worsening of existing depressive symptoms [15-17]. Women already receiving anti-depressant therapy are also commonly observed to have a recurrence of symptoms during this phase of the cycle $[18,19]$.

Neither progesterone blockade nor the truncation of the luteal phase (by mifepristone) appears to alter symptoms in women with MRD, suggesting that they are triggered by hormonal changes before the late luteal phase, especially in women with a history of depression [20]. This is also consistent with reports that the suppression of ovulation could result in the prevention of cyclic mood disturbance and the remission of MRD. It is also interesting to note that some of the women taking mifepristone did not have MRD when the menstrual cycle started again, indicating the existence of distinct subgroups of treatment vulnerability. 
Gonadotropin-releasing hormone (GnRH) agonists (leuprolide) used to suppress ovarian function in gynecological disorders, have been found to produce hypo-estrogenic side effects, for example vasomotor instability and vaginal dryness [21]; however, findings relating to mood response are inconsistent, with some women reporting the onset of major depression, and some women with preexisting MRD experiencing remission of symptoms [21-24]. Schmidt et al. [25] further observed that adding estradiol or progesterone to leuprolide, led to a recurrence of symptoms or an increase in depressive symptomatology in women with MRD compared to controls. This suggests that there is a selective sensitivity of women with menstrual cycle-related mood disorders (compared to controls) to the effects of gonadal steroids, and that in women with MRD the occurrence of affective disorder could represent an abnormal response to normal hormonal fluctuations.

Reduction in progesterone metabolites, especially 3 $\alpha$-pregnane neuroactive steroids has recently been associated specifically with mood disorder (see Refs. [26,27] for reviews). Both, 3 $\alpha$, 5 $\alpha$-THP (allopregnanolone) and $3 \alpha, 5 \beta$-THP were found to be decreased in patients suffering from major depression, whereas an increase was observed in $3 \beta, 5 \alpha$-THP which may act as a functional antagonist for these GABA-agonistic steroids. Levels could be normalized by successful treatment with antidepressants. Regarding MRD, lower luteal phase allopregnanolone levels has been associated with increased symptom severity [28,29], and an increase in allopregnanolone and $5 \alpha$ dihydroprogesterone (5 $\alpha$-DHP) has been associated with improved symptom ratings in patients with MRD [30]. Bicikova et al. have also reported low concentrations of allopregnanolone in patients with MRD but in the follicular phase only [31]. On the other hand, other studies have reported no variation of allopregnanolone in the luteal phase of patients with MRD [30,32], or even greater luteal phase allopregnanolone [33] and decreased allopregnanolone following treatment and improvement in symptomatology [34]. Several methodological differences may underlie these inconsistent findings, for example, failure to employ strict DSM diagnostic criteria [32] and to assess prior psychiatric disorders in MRD and control subjects [30,32], duration of MRD, absence of cycle phase evaluation or differences in blood sampling procedures and assay sensitivity [33], as well as difference in pharmacokinetic properties (see below). Another recent small study does not 
support the hypothesis that neurosteroid suppression (consecutive to low-dose OC administration) could engender mood effects, at least in psychologically healthy women [35]. One possibility is that altered neurosteroids provoke adverse mood symptoms only in women predisposed to affective disorders. There is currently no conclusive evidence to suggest that the normalization of neuroactive steroid levels is essential for the clinical response, or that a lack of effect on neuroactive steroid concentrations (as observed after non-pharmacological treatment) precludes antidepressant efficacy (see Ref. [36] for recent review). Clearly additional studies are needed to ascertain the clinical significance of reduced progesterone metabolites.

Hence, despite the evidence for a role of the gonadal hormones in the pathophysiology of MRD, it is generally agreed that neither a deficiency nor an excess in estradiol, progesterone or its reduced metabolites is etiologically relevant to these disorders. On the other hand, there is some indication that some women may be more sensitive to the mood modulatory effects of gonadal hormones and their neuroactive metabolites, and that this metabolism could be altered in MRD.

\section{Pregnancy}

Serum levels of estrogens (estrone, estradiol and estriol) as well as progesterone and most of its reduced metabolites $[37,38]$ increase rapidly during pregnancy, although smoking may lower estriol levels by $20 \%$ or more. After parturition, levels of all steroids drop sharply, especially progesterone and its reduced metabolite, $5 \alpha \mathrm{DHP}$, as well as estrogen whose levels decrease dramatically while maintaining a level sufficient for prolactin secretion for two days. During lactation, estradiol levels decrease to postmenopausal levels (see Ref. [39] for review). With regard to associated mood changes, longitudinal studies suggest a high risk of depression (14-18\%) between 32-weeks of pregnancy and 13 weeks postpartum [40-42]) (Table 1). Pregnancy rather than childbirth appears to be the factor that triggers depression in nondepressed women, with childbirth appearing more likely to be followed by improvement in depressed women [42]. As for MRD, the role of progesterone reduced metabolites has been investigated in depression related to pregnancy and postpartum. A tendency for increased concentrations of $5 \alpha \mathrm{DHP}$, and progesterone, has been reported in women 
with depression during the latter half of pregnancy, and in women with depressive symptomatology at 3 days postpartum compared with nondepressed women [37,38], as well as low levels of $3 \alpha, 5 \alpha-$ THP [45] although not systematically [38].

Hence, peak depression rates are reported during the last 3-6 weeks of pregnancy, when steroid levels are high, and in the early postpartum period, when steroid levels are low. The lowest rates are observed at the beginning of pregnancy or in the late postpartum period when levels are stabilized [41,42]. Rate of change in hormonal levels rather than absolute values may in fact be the key determinant as well as other factors linked to hormonal variability such as breastfeeding. It is interesting to note that while breastfeeding has been linked to the onset of major depression [40], bottle-feeding has been associated with depressive symptoms and major depression [17,46-48]. Although little is known from these follow-up studies about previous treatment, it would appear that women with recurrent major depression appear to be at especially high risk for relapse during pregnancy, especially those who discontinue antidepressant medication around the time of conception, with relapse rates of up to $75 \%[49,50]$.

A small double-blind trial [51] involving 16 euthymic women (with and without a history of PPD) treated with a GnRH agonist, followed by transient addition of estradiol and progesterone, concluded that estrogen and progesterone may be involved in the development of PPD in a subgroup of women (women with a history of PPD have a differential vulnerability to gonadal steroids compared to women without a history of PPD).

\section{Menopause}

Variability in study designs, sample subjects, definitions of menopausal status, and absence of standardized assessment of psychiatric symptoms has led to some inconsistent findings regarding the association between the menopausal transition and concomitant vulnerability to depressive symptoms. However, the most recent longitudinal, community-based studies suggest perimenopausal transition rather than menopause itself to be the point of increased vulnerability for depressive episodes [52-57] even in the absence of a history of depression [58,59] or in 
asymptomatic women [59]. Vasomotor symptoms (directly attributable to menopausal estrogen withdrawal) have been observed to increase the risk of depressive symptoms in perimenopausal women but not in pre- or postmenopausal women in primary care [60] and also in a population sample, but they were not shown to be independently associated with diagnosed depressive disorder in population [57,58]. In addition, the observation that estrogen therapy (ET) may improve depressive symptoms even in women without menopausal symptoms [61-63] also suggests that perimenopausal vulnerability to depression may be independent of vasomotor symptoms.

Lifetime history of depression has been associated with early perimenopause [54,64] and women undergoing natural menopause before age 47 are two to three times more likely to have been treated for depression. Recent findings also suggest a relationship between episodic alterations in ovarian function and depressive symptomatology in some perimenopausal women, with improvements in ovarian function being associated with remission of depressive symptoms [65]. The question, however, remains as to whether depression is the result of lifelong low exposure to steroid hormones due to early decline in ovarian function or if depression permanently alters hypothalamicpituitary-gonadal axis regulation to stressful events [65].

Reports of depression following surgical menopause are inconsistent, possibly due to the difference in delay between surgery and the psychiatric examination [66]) or the type of surgery, with bilateral oophorectomy causing rapid depletion of estrogens and androgens to lower than natural menopause levels [67]. In a recent prospective study focusing on the menopause transition (with a 11-year follow-up), a higher depressive symptomatology has been reported for women who have undergone surgical menopause (after hysterectomy and/ or oophorectomy) [55]. In oophorectomized women the risk of depression may be higher compared with women who underwent natural menopause, with depression onset occurring rapidly after the ovariectomy [68,69]. Maintaining the ovaries of premenopausal women who have had a hysterectomy may protect against subsequent mood disorder $[68,70]$ although hysterectomy may also cause premature ovarian failure. Being the result of prolonged heavy periods, chronic pelvic pain, and severe MRD, depressed mood is, however, 
also observed in women before hysterectomy [71-74]. Hysterectomy may thus improve mood, except for women with preexisting psychiatric illness or predisposing personality problems, in whom depressed mood may persist or re-occur in response to the stress associated with surgery [72,74]. Finally, thirty eight percent of women experiencing induced menopause due to treatment of breast cancer have been observed to develop major depression and 95\% dysphoria within the first 6 months of treatment [75].

\section{IMPACT OF EXOGENOUS ENDOCRINE EXPOSURE}

\section{Oral contraceptives}

A recent review concluded that OC users experience less variability in mood across the menstrual cycle, and fewer depressive symptoms during menstruation [76]. A minority of women do, however, experience negative mood changes. Potential mediators of the relation between OCs and mood are age, preexisting psychiatric disorder, history of depression or hormonal-related symptoms (related to premenstrual phase, dysmenorrhoea, pregnancy, or postpartum), and OC type (dosage and content). A lower ratio of progesterone to estrogen is associated with more negative mood change in women with a history of MRD, and a higher ratio is associated with increased negative mood in women without such a history, suggesting a distinct biological vulnerability for women with a history of MRD. Major depression and anxiety disorder have been observed in women with no prior psychiatric history 1-3 months after Norplant insertion (a long-acting subdermal implant with progesterone-like effects). Symptoms were found to worsen over time but disappeared 1-2 months after Norplant removal [77].

In a nested case-control study within a community-based cohort of 976 premenopausal women [78], $16.3 \%$ of OC users reported premenstrual mood deterioration, while $12.3 \%$ reported improvement. An adjusted regression model found previous depression to be the only significant predictor of OCrelated mood deterioration while early-onset premenstrual mood disturbance and dysmenorrhea were observed to be significant predictors of OC-related mood improvement. Using estradiol, progestins or OC may thus be therapeutic for patients with MRD [79,80]. Treatment may, however, 
be less effective for women suffering from severe MRD, for whom selective serotonin reuptake inhibitors (SSRIs) may be preferable [81]. Randomized controlled trials (RCTs) are clearly needed in this area, especially for the more recent OCs.

\section{Post-partum HT}

The use of HT as a modulator of PPD has been reported in the register of clinical trials maintained and updated by the Cochrane Pregnancy and Childbirth Group [82]. Synthetic progestogens given within 48 hours of delivery and over 8-12 weeks are associated with significantly higher depressive symptomatology than placebo, whereas ET in severely depressed women led to improvement. A positive and rapid (2-13 weeks) effect for ET has also been reported for severe PPD and postpartum psychosis [83,84]. Improvement is generally rapid, with one RCT of 61 women with PPD reporting statistically and clinically significant reductions in depressive symptoms after 1 and 3 months of HRT consisting of $17 \beta$-estradiol with added dydrogesterones (for 12 days each month) [83]. The treatment response was sustained over the next 5 months. However, half of the women were also taking antidepressants; hence, it remains uncertain as to whether estrogen should be used as monotherapy or as an ancillary therapy. A more recent study evaluated 23 women with a major depressive disorder with postpartum onset. Depressive symptoms diminished rapidly with oral $17 \beta$ estradiol, and after 2 weeks depression scores indicated clinical recovery in 83\% of patients [84]. As for MRD and perimenopausal depression, the positive effects on puerperal depression are mostly reported with transdermal estradiol [85].

\section{Menopausal HT}

A large number of studies have shown a significant amelioration of mood in perimenopausal and postmenopausal women treated with HT, although not systematically. The discrepancies probably result from differences in HT use [86]; cohorts [87,88]; methods used to determine menopausal and hormonal status [89]; clinical features of the menopause that is, whether symptomatic [90,91], natural or following oophorectomy [92]; and criteria for the target psychiatric disorders [93,94]. 
Interstudy variability is further amplified by differences in sample size, methods of statistical analysis, and variable reliability of retrospective reporting of symptoms (e.g. recall bias, healthy user bias, compliance bias, expectancy effects, and influence of previous psychiatric disorder) [88]. Despite methodological limitations and contradictory reports regarding the beneficial effect of HT on depression, a meta-analysis of 38 RCTs or cohort studies found that the overall effect size (ES) for HT was 0.68 [87] indicating that even if interstudy differences and potential confounders were considered, that HT lowered the rate of depressed mood by 76\%. Estrogen [mostly oral conjugated equine estrogen [CEE]) was found to have a moderate to large effect in reduction of depressed mood (ES=0.69), while progesterone alone, or combined with estrogen, was associated with smaller reductions (ES=0.39 and 0.45, respectively). Androgen alone, or combined with estrogen was associated with the greatest reduction in depressed mood ( $\mathrm{ES}=1.37$ and 0.90, respectively). ES was greater in perimenopausal than in postmenopausal women (1.81 vs. 0.9$)$ and in natural compared to surgical menopause (1.52 vs. 0.77). Treatment longer than 8 months was associated with the greatest improvement. Although most of the studies included in this meta-analysis used depression measures with documented reliability and validity, few reported subjects with significant levels of depression. The true effectiveness of HT for patients with significant levels of depression may thus have been underestimated.

Two recent large RCTs investigating the long-term effect of HT on mood in postmenopausal women, the Heart and Estrogen/progestin Replacement Study (HERS) and the Women's Health Initiative (WHI) study. They evaluated the effect of a 36-month-treatment with CEE+ medroxyprogesterone acetate (MPA, which is probably not the most efficient in terms of neuroprotection) in older post-menopausal women (who are probably not the most sensitive targets). In both studies, quality of life or “psychiatric distress” (rather than depressive symptoms) was assessed using the Burnam screen [95]. In HERS, HT had mixed effects among 2763 postmenopausal women depending on the presence of menopausal symptoms. Women without flushes had greater declines in physical measures, while women with flushes improved in quality- 
of-life items relating to mood [90]. Flushes are more common in thin women, and after menopause peripheral aromatization of androgens in adipose tissue is the primary source of endogenous estrogen. This could thus reflect a threshold in the level of biologically significant doses of estrogens beyond which additional exogenous estrogens would have negligible effects on measures of mood. In the WHI study, HT did not improve "psychiatric distress” in 16,608 postmenopausal women, most of them did not have menopausal symptoms [96]. The Burnam screen has, however, serious short-comings and is inadequate for this type of study; subjects frequently complained that the items were confusing, and the scale as a whole has very poor sensitivity and positive predictive value for major depression, dysthymia and mood disorder [97].

Most recent robust RCTs in women with clinically diagnosed depression report a positive effect of ET (Table 2). A full or partial therapeutic response was mostly seen in women with perimenopause-related major or minor depression or dysthymia, who receive transdermal estradiol [61]. Complete remission of symptoms persisted after a 4-week washout period, although somatic complaints increased in frequency and intensity [62]. Evidence for an ET antidepressant response has, however, been found to be weaker in postmenopausal compared to perimenopausal women $[63,98]$. It is still unclear, however, as to whether postmenopausal women require higher doses and/or prolonged treatment to obtain a satisfactory antidepressant effect. They could also be unresponsive to the mood-enhancing effects of estradiol, suggesting the existence of a critical window of estrogen susceptibility in the perimenopausal period during which HT could have maximal antidepressant and neuroprotective effects [99,100].

It should be noted that effects vary according to the estrogen derivative used (CEE being less effective than 17- $\beta$-estradiol) and the administration mode, as oral (but not transdermal) drugs are metabolized by the liver, reducing brain concentrations. Addition of androgens allows the reduction of the dose of estrogen needed to control vasomotor symptoms or enhance mood improvement, whereas synthetic progestins (especially MPA) could be antagonistic to estrogen and mitigate its mood-enhancing effect [101,102]. Sequential HT may produce periodic increases in depressive and 
anxiety symptoms (which has been related to the progesterone metabolite allopregnanolone [103]), and this may improve with continuous combined HT therapy. A negative effect on mood was reported in nondepressed postmenopausal women treated with cyclic progestagens in combination with estrogen, whereas no significant change or an improvement in mood was observed with estrogen alone [104-106]. This is also compatible with a recent large cross-sectional study of 6602 postmenopausal women in whom a decreased risk of depressive symptoms was reported in current estrogen users but not in combined estrogen plus progestin users [107].

\section{Anti-hormone treatment and depressive symptomatology}

Many estrogen-related diseases are treated with antiestrogenic drugs. Selective Estrogen Receptor Modulators (SERMs), such as tamoxifen, are synthetic, non-hormonal compounds acting as estrogen agonists on some tissues and antagonists on others. They are widely used as an adjuvant therapy for breast cancer. In a prospective clinical trial of 257 women with breast cancer, 15\% of the women treated with tamoxifen had symptoms of depression compared to $3 \%$ in controls in the 6-12 months following treatment [108]. In a more recent multicenter study of 11,064 women treated for 5 years, no difference was found between tamoxifen and placebo groups with regard to depression and overall quality of life. However, tamoxifen subjects showed consistent increases in vasomotor and gynecological symptoms [109]. Hence, depressed symptoms appear to be related to short-term use, whereas long-term use is associated only with vasomotor symptoms. An RCT with another SERM, raloxifene, found lowered anxiety levels but no effect on quality of life or depressed mood in asymptomatic, post-menopausal women [110-112].

The xeno-estrogen, diethylstilbestrol (DES) which has been used in the treatment of breast and prostate cancer, frequently causes irritability and more rarely, depression. Although not well substantiated, there is some evidence to suggest that DES may modulate late-life vulnerability to depression. In a large RCT including 530 adult men and women exposed to DES in utero, an increased vulnerability (by twofold) was reported by general practitioners (unaware of DES status) 
for depression, anxiety and eating disorders independently of genital anomalies and somatic complications of DES exposure [113]. An increased prevalence of major depression was also observed in 50 DES-exposed women compared to 50 unexposed sisters, although in a comparison with 43 women experiencing other gynecologic problems, the excess of risk of depression could not attributed specifically to DES [114]. A smaller study also found a higher non-significant prevalence in major depressive disorder and a significant increase in recurrence of depressive episodes in 27 DES-exposed compared to nonexposed brothers (44 vs. 26\%) [115]. On the other hand, no association was found with regard to self-reported mental illness in a study of 5686 women of whom 69\% were exposed to DES [116]. Overall there is currently insufficient evidence to permit the drawing of any conclusions in relation to the effects of DES exposure.

\section{ENDOCRINE FLUCTUATIONS AND DEPRESSION: A CONTINUUM MODEL}

Is there a common pattern of vulnerability regarding reproductive cycle-associated depressive symptoms?

Past history of depression is a strong predictor of subsequent depressive episodes (see Ref. [117] for meta-analysis). However, it is still uncertain as to whether hormone-related depression predicts subsequent hormone-related depression thus suggesting the existence of a continuum of hormonal vulnerability for reproductive-cycle-associated depressive symptoms. Small sample size, the limits of retrospective evaluation of MRD, the absence of measures of perimenopausal hormonal ovarian function and standardized diagnosis of depression, undoubtedly contribute to the observed inconsistency in results reported so far.

Numerous studies have shown that women who suffer from affective disorders following one reproductive event may be more vulnerable to relapse associated with others. Increased risk for postpartum depressive symptoms has been associated with MRD [118-122], psychiatric symptoms during pregnancy [121-125] or prior PPD [118,121,122,126,127], or, more rarely, mood instability at puberty $[128,129]$ or secondary to OCs $[121]$. Women who report a high level of depressive symtpomatology during menopause are also more likely to report past depression associated with 
MRD, OC-related dysphoria, postnatal blues, and PPD, than those who did not report current psychiatric distress [55,56,130-132].

Nevertheless, although frequent, the presence of one episode of mood disorder related to reproductive endocrine functioning does not predict the uniform occurrence of depression during a subsequent period of hormonal change. Recent studies notably indicate that a high percentage of women experience their first depressive episode during perimenopause [57-59,133]. Richards et al. [133] also suggested that neither MRD cyclicity nor premenstrual dysphoria at the perimenopause was an invariant accompaniment of perimenopausal depression. However, they also reported a higher-than-expected rate of MRD cyclicity and premenstrual dysphoria in perimenopausal depressed women (26\% of women experienced both conditions).

The fact that only some women who suffer from mood disorders in one phase of the reproductive cycle are also more likely to have a recurrence of symptoms in subsequent phases is suggestive of a specific inherent individual biological vulnerability. This also suggests that such vulnerability may constitute a stable trait [12,40,130,132], which may be expressed as symptoms in response to different triggers (biological or environmental). Individual variation in biological vulnerability and an intrinsic abnormal reaction to normal changes in reproductive hormones could, thus, contribute to a range of psychiatric symptoms in some subgroups of women even in the context of normal ovarian function $[129,134]$.

If changes in gonadal steroid levels trigger hormone-associated depressive symptoms, why does this not occur in all women at every phase of change?

All women who have antecedents of hormone-sensitive depression have not systematically experienced depression at other periods of hormonal change. What is the underlying cause of this phenotypic response to a given biological stimulus? Although the context dependency of steroid action has been established, a further source of differences in response phenotype may also be attributed to genotype. Known polymorphisms in gonadal steroid receptors have been shown to alter receptor transcriptional efficiency but also to be associated with different hormone-related 
pathologies, such as breast cancer, cardiovascular pathologies and osteoporotic fractures. This association has not, however, been fully explored in relation to mood disorders. At the present time, the role of ER polymorphisms in depression has only been investigated in two case control studies. A significant association was observed between depression and two distinct single-nucleotide polymorphisms of ER $\alpha$ in women with major depression but not in men $[135,136]$. ER polymorphisms may also be involved in HT response, a possibility which has not yet been evaluated. The importance of family or genetic factors in the etiology of MRD or postpartum mood disorders has already been suggested [137,138]. Recently, Rubinow and Schmidt [139] have also shown that a region of the ER $\alpha$ gene containing multiple polymorphic alleles was associated with MRD, thus supporting the hypothesis that the effects of multiple genes may interact in creating a dysphoric behavioral response to normal gonadal steroid levels.

Genetic polymorphism variability, interacting with lifetime hormonal exposure (see below) may determine systemic reactions to multiple environmental stressors and, hence, enhance or inhibit the onset of mood disorders. Within a multifactorial aetiological model, hormone-associated mood disorders may thus be construed as a clinical endpoint triggered by reproductive endocrine stimuli in persons susceptible to behavioral state changes due to the interaction of biological conditions, antecedent experimental events, vulnerability to depression (e.g. serotonergic dysregulation), and genetic as well as other environmental factors. Complex multi-factorial analyses incorporating detailed reproductive histories, the long-term effects of natural steroids, genetic vulnerability, and longitudinal observations of depressive symptomatology, are currently needed in order to adequately explore this hypothesis.

\section{Is it possible to identify women at risk of hormone-related depression?}

Direct observation of circulating hormonal levels is not likely to be an useful biological marker for a number of reasons. In animals, ovarian steroids have higher concentrations in brain than plasma, 
and the turnover rate of brain sequestration of blood-borne sex steroids is also high [140]. Serum levels are not very informative with regard to the etiology of disorders associated with decline in circulating estrogen levels due to the difference in estrogen, progesterone and testosterone kinetic diffusion rates across the blood brain barrier; the possibility of distinct affinity binding and steroid receptor content in the brain; the presence of localized brain neurosteroids and localized metabolism via aromatase $[141,142]$. The rate of change of hormonal levels rather than the absolute value might be more relevant to psychiatric outcome as suggested by the prevalence of depression during pregnancy, postpartum and following surgical menopause. More clinically relevant measures of endogenous steroid effects at the level of specific tissues are needed. Studies of other hormonedependent pathologies such as osteoporosis and breast cancer, have already identified clinical markers that reflect increased lifelong estrogen exposure for example, earlier age at menarche, nulliparity, late menopause, climacteric obesity, and exogenous endocrine exposure.

Fluctuations in estrogen levels linked to these specific markers have been associated with the risk of developing hormone-dependent pathologies leading to the now widely-used concepts of 'cumulative hormonal exposure' and 'hormonal windows'. For example, studies of the impact of reproductive factors on the etiology of hormone-sensitive breast cancer have increasingly relied on mathematical models that combine multiple markers into a single equation; these combined indices providing greater predictive power than individual markers [143,144]. This methodology has produced what is now a well-established model incorporating positive endogenous risk factors (early age at menarche, nulliparity, late age at first full-term pregnancy, late age at any birth, low parity among parous women and late age at menopause), and certain exogenous risk factors (notably OCs and HT) (see Refs. [145,146] for reviews). This model has also been widely used for osteoporosis to demonstrate that higher bone density is associated with a longer endogenous or exogenous hormonal exposure [147,148].

While the utility of global clinical markers of estrogen has been firmly established for other hormone dependent disorders, we do not currently know whether they may contribute to our understanding of the effects of estrogens on brain functioning. This methodology is now being 
applied in the area of cognitive ageing where it has been suggested that no individual marker is as potent as a combined index for prediction of cognitive dysfunction, indicating that the effects of steroids on brain may be more apparent when the cumulative effects of exposure are evaluated (see for review [149]). No such study has as yet applied such a cumulative model to psychiatric disorder, although life-long low exposure to steroid hormones has been reported to be associated with lifetime history of depression [54,64].

\section{THE USE OF HORMONAL THERAPIES IN CLINICAL PRACTICE}

A growing body of literature attests to the significant impact of hormonal exposure on central nervous system functioning throughout the life course in women and raises the question of whether hormonal therapies may be useful in treating depression. Most studies reported that postmenopausal women appear to be more commonly nonrespondive to serotonergic antidepressant therapy than younger women [150-154], although not systematically $[155,156]$. Some studies have investigated the possible effect of estrogen as an adjunct treatment for postmenopausal depression. Whereas an early small study failed to show any benefit when CEE was added to the tricyclic antidepressant imipramine in pre- and post-menopausal women with major depression [157], subsequent reports have suggested that the antidepressant effect of SSRIs may be improved by concurrent estrogen treatment [158-161]. One retrospective non-controlled study did not reproduce this finding. However, 37\% of the women in the HT group were also using intermittent progesterone [162]. The effectiveness of ET requires further validation in large RCTs before its routine use in clinical practice can be recommended. Research in this area has, however, recently stagnated due to the side effects of hormonal treatments observed in the WHI study [163]. While the hormonal treatments used in the American WHI study do not necessarily correspond to current European practice, and because the subjects were treated as a group and not according to their individual health profiles, there has been a general reticence to continue with this type of treatment. There is also an underlying assumption that a small increase in the risk of hormone-dependant cancer or cardiovascular disorder (but not on mortality rates [164]) is inevitably a far greater health concern 
than major depression.

In terms of screening at-risk women, reproductive history clearly have an important role to play. Women obviously do not arrive at menopause with equal risk of psychiatric disorder or equal susceptibility to the effects of HT, although this point has not been taken into account in the major RCTs conducted to date such as the HERS or WHI study [90,96]. Why some women seem more vulnerable to neuropsychiatric disorder remains poorly understood; however, certain implications of this observation may nonetheless be incorporated into clinical practice. The description of reproductive life events, evaluation of past history of psychiatric disorders and their timing in relation to reproductive stages should be a routine part of the mental status examination of women and should be taken into account in formulating a treatment strategy. This could help in predicting whether a patient is vulnerable to depressive episodes as a function of changes in hormonal levels. In 2001, the Treatment of Depression in Women Expert Consensus Guidelines were published to provide recommendations for management and treatment of four depressive conditions specific to women (PMDD, depression in pregnancy, PPD and depression related to perimenopause) [50]. HT was recommended as first-line therapy by $69 \%$ of experts for first episodes of mild and moderate depression occurring at perimenopause, antidepressants being recommended as the second option.

HT is still the first line treatment for the $75 \%$ of women who experience menopausal symptoms at the perimenopausal stage. Although no trials have focused specifically on women in this age group most likely to require menopausal symptom relief, it is increasingly acknowledged that the risks are probably negligible (see Refs. [165,166] for recent reviews), for women with menopausal symptoms who typically do not require ongoing use of estrogen therapy beyond the 5 year-period after which the cumulative risk of breast cancer and cardiovascular disease may become significant. The use of HT appears to be most appropriate for depressive perimenopausal women with a history of mood disorders associated with reproductive fluctuations or if vasomotor symptoms are present. In women whose depression or hot flushes are not responsive to antidepressants, HT may be 
considered as adjunctive treatment. Obviously recognized contraindications and health risks of HT (e.g. hormone-dependent cancer, (cardio)vascular disease [167]) have to be taken into account [168]. Natural formulations (micronized progesterone, transdermal 17- $\beta$-estradiol) are preferable given their probable lower side effects notably in relation to breast cancer [169] and greater impact on mood disorders. Hormonal treatment may also prove valuable in the treatment of the $30 \%$ of patients who are resistant to conventional anti-depressant therapy. Selection for hormonal treatment in the postgenomic era may eventually be based on genetic markers identifying populations responsive to antidepressants, to estrogen, or to combinations of antidepressants and estrogens. This type of individually-tailored clinical strategy appears on present evidence to provide a more rational and personalized approach to the hormonal treatment of depression in women [170].

Declaration of interest: None. 


\section{REFERENCES}

[1] Robins LN, Helzer JE, Weissman MM, Orvaschel H, Gruenberg E, Burke Jd JR, Regier DA. Lifetime prevalence of specific psychiatric disorders in three sites. Arch Gen Psychiatry 1984;41:949-958.

[2] Kessler RC, McGonagle KA, Swartz M, Blazer DG, Nelson CB. Sex and depression in the National Comorbidity Survey. I: Lifetime prevalence, chronicity and recurrence. J Affect Disord 1993;29:85-96.

[3] Ritchie K, Artero S, Beluche I, Ancelin ML, Mann A, Dupuy AM, Malafosse A, Boulenger JP. Prevalence of DSM-IV psychiatric disorder in the French elderly population. $\mathrm{Br} \mathrm{J}$ Psychiatry 2004;184:147-52.

[4] Alonso J, Angermeyer MC, Bernert S, Bruffaerts R, Brugha TS, Bryson H, Girolamo G, Graaf R, Demyttenaere K, Gasquet I, Haro JM, Katz SJ, Kessler RC, Kovess V, Lepine JP, Ormel J, Polidori G, Russo LJ, Vilagut G, Almansa J, Arbabzadeh-Bouchez S, Autonell J, Bernal M, Buist-Bouwman MA, Codony M, Domingo-Salvany A, Ferrer M, Joo SS, Martinez-Alonso M, Matschinger H, Mazzi F, Morgan Z, Morosini P, Palacin C, Romera B, Taub N, Vollebergh WA. Prevalence of mental disorders in Europe: results from the European Study of the Epidemiology of Mental Disorders (ESEMeD) project. Acta Psychiatr Scand Suppl 2004:21-7.

[5] Garcia-Segura LM, Azcoitia I, DonCarlos LL. Neuroprotection by estradiol. Prog Neurobiol 2001;63:29-60.

[6] Behl C. Oestrogen as a neuroprotective hormone. Nat Rev Neurosci 2002;3:433-42.

[7] Burt VK, Stein K. Epidemiology of depression throughout the female life cycle. J Clin Psychiatry 2002;63:9-15.

[8] Kornstein SG. The evaluation and management of depression in women across the life span. J Clin Psychiatry 2001;62:11-7.

[9] Noble RE. Depression in women. Metabolism 2005;54:49-52.

[10] American Psychiatric Association. Diagnostic and Statistical Manual of Mental Disorders (DSM-IV). Washington, DC, American Psychiatric Association, 1994.

[11] Steiner M, Pearlstein T, Cohen LS, Endicott J, Kornstein SG, Roberts C, Roberts DL, Yonkers K. Expert guidelines for the treatment of severe PMS, PMDD, and comorbidities: the role of SSRIs. J Womens Health (Larchmt) 2006;15:57-69. 
[12] Halbreich U. The etiology, biology, and evolving pathology of premenstrual syndromes. Psychoneuroendocrinology 2003;28 Suppl 3:55-99.

[13] Bebbington PE, Dunn G, Jenkins R, Lewis G, Brugha T, Farrell M, Meltzer H. The influence of age and sex on the prevalence of depressive conditions: report from the National Survey of Psychiatric Morbidity. Psychol Med 1998;28:9-19.

[14] Halbreich U, Borenstein J, Pearlstein T, Kahn LS. The prevalence, impairment, impact, and burden of premenstrual dysphoric disorder. Psychoneuroendocrinology 2003;28:1-23.

[15] Halbreich U. Premenstrual dysphoric disorders: a diversified cluster of vulnerability traits to depression. Acta. Psychiatr. Scand. 1997;95:169-176.

[16] Rubinow DR, Roy-Byrne P, Hoban MC, Grover GN, Stambler N, Post RM. Premenstrual mood changes. Characteristic patterns in women with and without premenstrual syndrome. J Affect Disord 1986;10:85-90.

[17] Harlow BL, Cohen LS, Otto MW, Spiegelman D, Cramer DW. Early life menstrual characteristics and pregnancy experiences among women with and without major depression: the Harvard study of moods and cycles. J Affect Disord 2004;79:167-76.

[18] Kimmel S, Gonsalves L, Youngs D, Gidwani G. Fluctuating levels of antidepressants premenstrually. J Psychosom Obstet Gynaecol 1992;13:277-280.

[19] Jensvold MF, Reed K, Jarett DB, Hamilton JA. Menstrual cycle-related depressive symptoms treated with variable antidepressant dosage. J Wom Health 1992;1:109-115.

[20] Schmidt PJ, Nieman LK, Grover GN, Muller KL, Merriam GR, Rubinow DR. Lack of effect of induced menses on symptoms in women with premenstrual syndrome. N Engl J Med 1991;324:1174-9.

[21] Warnock JK, Bundren JC. Anxiety and mood disorders associated with gonadotropinreleasing hormone agonist therapy. Psychopharmacol Bull 1997;33:311-6.

[22] Brown CS, Ling FW, Andersen RN, Farmer RG, Arheart KL. Efficacy of depot leuprolide in premenstrual syndrome: effect of symptom severity and type in a controlled trial. Obstet Gynecol 1994;84:779-86.

[23] Freeman EW, Sondheimer SJ, Rickels K, Albert J. Gonadotropin-releasing hormone agonist in treatment of premenstrual symptoms with and without comorbidity of depression: a pilot study. J Clin Psychiatry 1993;54:192-5.

[24] Wyatt KM, Dimmock PW, Ismail KM, Jones PW, O'Brien PM. The effectiveness of GnRHa with and without 'add-back' therapy in treating premenstrual syndrome: a meta analysis. Bjog 2004;111:585-93.

[25] Schmidt PJ, Nieman LK, Danaceau MA, Adams LF, Rubinow DR. Differential behavioral effects of gonadal steroids in women with and in those without premenstrual syndrome. $\mathrm{N}$ Engl J Med 1998;338:209-16. 
[26] Rupprecht R. Neuroactive steroids: mechanisms of action and neuropsychopharmacological properties. Psychoneuroendocrinology 2003;28:139-68.

[27] Strous RD, Maayan R, Weizman A. The relevance of neurosteroids to clinical psychiatry: from the laboratory to the bedside. Eur Neuropsychopharmacol 2006;16:155-69.

[28] Rapkin AJ, Morgan M, Goldman L, Brann DW, Simone D, Mahesh VB. Progesterone metabolite allopregnanolone in women with premenstrual syndrome. Obstet Gynecol 1997;90:709-14.

[29] Monteleone P, Luisi S, Tonetti A, Bernardi F, Genazzani AD, Luisi M, Petraglia F, Genazzani AR. Allopregnanolone concentrations and premenstrual syndrome. Eur J Endocrinol 2000;142:269-73.

[30] Wang M, Seippel L, Purdy RH, Backstrom T. Relationship between symptom severity and steroid variation in women with premenstrual syndrome: study on serum pregnenolone, pregnenolone sulfate, 5 alpha-pregnane-3,20-dione and 3 alpha-hydroxy-5 alpha-pregnan20-one. J Clin Endocrinol Metab 1996;81:1076-82.

[31] Bicikova M, Dibbelt L, Hill M, Hampl R, Starka L. Allopregnanolone in women with premenstrual syndrome. Horm Metab Res 1998;30:227-30.

[32] Schmidt PJ, Purdy RH, Moore PH, Jr., Paul SM, Rubinow DR. Circulating levels of anxiolytic steroids in the luteal phase in women with premenstrual syndrome and in control subjects. J Clin Endocrinol Metab 1994;79:1256-60.

[33] Girdler SS, Straneva PA, Light KC, Pedersen CA, Morrow AL. Allopregnanolone levels and reactivity to mental stress in premenstrual dysphoric disorder. Biol Psychiatry 2001;49:788-97.

[34] Freeman EW, Frye CA, Rickels K, Martin PA, Smith SS. Allopregnanolone levels and symptom improvement in severe premenstrual syndrome. J Clin Psychopharmacol 2002;22:516-20.

[35] Rapkin AJ, Morgan M, Sogliano C, Biggio G, Concas A. Decreased neuroactive steroids induced by combined oral contraceptive pills are not associated with mood changes. Fertil Steril 2006;85:1371-8.

[36] Eser D, Schule C, Baghai TC, Romeo E, Uzunov DP, Rupprecht R. Neuroactive steroids and affective disorders. Pharmacol Biochem Behav 2006.

[37] Gilbert Evans SE, Ross LE, Sellers EM, Purdy RH, Romach MK. 3alpha-reduced neuroactive steroids and their precursors during pregnancy and the postpartum period. Gynecol Endocrinol 2005;21:268-79.

[38] Pearson Murphy BE, Steinberg SI, Hu FY, Allison CM. Neuroactive ring A-reduced metabolites of progesterone in human plasma during pregnancy: elevated levels of 5 alpha- 
dihydroprogesterone in depressed patients during the latter half of pregnancy. J Clin Endocrinol Metab 2001;86:5981-7.

[39] Brett M, Baxendale S. Motherhood and memory: a review. Psychoneuroendocrinology 2001;26:339-62.

[40] Pop VJ, Essed GG, de Geus CA, van Son MM, Komproe IH. Prevalence of post partum depression--or is it post-puerperium depression? Acta Obstet Gynecol Scand 1993;72:354-8.

[41] Josefsson A, Berg G, Nordin C, Sydsjo G. Prevalence of depressive symptoms in late pregnancy and postpartum. Acta Obstet Gynecol Scand 2001;80:251-5.

[42] Evans J, Heron J, Francomb H, Oke S, Golding J. Cohort study of depressed mood during pregnancy and after childbirth. BMJ 2001;323:257-60.

[43] Kumar R, Robson KM. A prospective study of emotional disorders in childbearing women. Br J Psychiatry 1984;144:35-47.

[44] Watson JP, Elliott SA, Rugg AJ, Brough DI. Psychiatric disorder in pregnancy and the first postnatal year. Br J Psychiatry 1984;144:453-62.

[45] Nappi RE, Petraglia F, Luisi S, Polatti F, Farina C, Genazzani AR. Serum allopregnanolone in women with postpartum "blues". Obstet Gynecol 2001;97:77-80.

[46] Yonkers KA, Ramin SM, Rush AJ, Navarrete CA, Carmody T, March D, Heartwell SF, Leveno KJ. Onset and persistence of postpartum depression in an inner-city maternal health clinic system. Am J Psychiatry 2001;158:1856-63.

[47] Hannah P, Adams D, Lee A, Glover V, Sandler M. Links between early post-partum mood and post-natal depression. Br J Psychiatry 1992;160:777-80.

[48] Lane A, Keville R, Morris M, Kinsella A, Turner M, Barry S. Postnatal depression and elation among mothers and their partners: prevalence and predictors. $\mathrm{Br} \mathrm{J}$ Psychiatry 1997;171:550-5.

[49] Cohen LS, Altshuler LL, Stowe ZN, Faraone SV. Reintroduction of antidepressant therapy across pregnancy in women who previously discontinued treatment. A preliminary retrospective study. Psychother Psychosom 2004;73:255-8.

[50] Altshuler LL, Cohen LS, Moline ML, Kahn DA, Carpenter D, Docherty JP. The Expert Consensus Guideline Series. Treatment of depression in women. Postgrad Med 2001:1-107.

[51] Bloch M, Schmidt PJ, Danaceau M, Murphy J, Nieman L, Rubinow DR. Effects of gonadal steroids in women with a history of postpartum depression. Am J Psychiatry 2000;157:92430.

[52] Avis NE, Brambilla D, McKinlay SM, Vass K. A longitudinal analysis of the association between menopause and depression. Results from the Massachusetts Women's Health Study. Ann Epidemiol 1994;4:214-20. 
[53] Maartens LW, Knottnerus JA, Pop VJ. Menopausal transition and increased depressive symptomatology: a community based prospective study. Maturitas 2002;42:195-200.

[54] Harlow BL, Wise LA, Otto MW, Soares CN, Cohen LS. Depression and its influence on reproductive endocrine and menstrual cycle markers associated with perimenopause: the Harvard Study of Moods and Cycles. Arch Gen Psychiatry 2003;60:29-36.

[55] Dennerstein L, Guthrie JR, Clark M, Lehert P, Henderson VW. A population-based study of depressed mood in middle-aged, Australian-born women. Menopause 2004;11:563-8.

[56] Freeman EW, Sammel MD, Liu L, Gracia CR, Nelson DB, Hollander L. Hormones and menopausal status as predictors of depression in women in transition to menopause. Arch Gen Psychiatry 2004;61:62-70.

[57] Freeman EW, Sammel MD, Lin H, Nelson DB. Associations of hormones and menopausal status with depressed mood in women with no history of depression. Arch Gen Psychiatry 2006;63:375-82.

[58] Cohen LS, Soares CN, Vitonis AF, Otto MW, Harlow BL. Risk for new onset of depression during the menopausal transition: the Harvard study of moods and cycles. Arch Gen Psychiatry 2006;63:385-90.

[59] Schmidt PJ, Haq N, Rubinow DR. A longitudinal evaluation of the relationship between reproductive status and mood in perimenopausal women. Am J Psychiatry 2004;161:223844.

[60] Joffe H, Hall JE, Soares CN, Hennen J, Reilly CJ, Carlson K, Cohen LS. Vasomotor symptoms are associated with depression in perimenopausal women seeking primary care. Menopause 2002;9:392-8.

[61] Schmidt PJ, Nieman L, Danaceau MA, Tobin MB, Roca CA, Murphy JH, Rubinow DR. Estrogen replacement in perimenopause-related depression: a preliminary report. Am. J. Obstet. Gynecol. 2000;183:414-420.

[62] Soares CN, Almeida OP, Joffe H, Cohen LS. Efficacy of estradiol for the treatment of depressive disorders in perimenopausal women: a double-blind, randomized, placebocontrolled trial. Arch. Gen. Psychiatry. 2001;58:529-534.

[63] Cohen LS, Soares CN, Poitras JR, Prouty J, Alexander AB, Shifren JL. Short-term use of estradiol for depression in perimenopausal and postmenopausal women: a preliminary report. Am J Psychiatry 2003;160:1519-22.

[64] Harlow BL, Cramer DW, Annis KM, Xu H. Association of medically treated depression and age at natural menopause. Does "incessant" ovulation increase risk for early menopause? Am J Epidemiol 1995;141:1170-6.

[65] Daly RC, Danaceau MA, Rubinow DR, Schmidt PJ. Concordant restoration of ovarian function and mood in perimenopausal depression. Am J Psychiatry 2003;160:1842-6. 
[66] Kritz-Silverstein D, Von Muhlen DG, Ganiats TG, Barrett-Connor E. Hysterectomy status, estrogen use and quality of life in older women: the Rancho Bernardo study. Qual Life Res 2004;13:55-62.

[67] Laughlin GA, Barrett-Connor E, Kritz-Silverstein D, Von Muhlen D. Hysterectomy, oophorectomy, and endogenous sex hormone levels in older women: the Rancho Bernardo Study. J. Clin. Endocrinol. Metab. 2000;85:645-651.

[68] Sherwin BB, Gelfand MM. Sex steroids and affect in the surgical menopause: a doubleblind, cross-over study. Psychoneuroendocrinology 1985;10:325-335.

[69] Taylor M. Psychological consequences of surgical menopause. J. Reprod. Med. 2001;46:317-324.

[70] Nathorst-Boos J, von Schoultz B, Carlstrom K. Elective ovarian removal and estrogen replacement therapy--effects on sexual life, psychological well-being and androgen status. $\mathrm{J}$ Psychosom Obstet Gynaecol 1993;14:283-93.

[71] Ballinger CB. Psychiatric morbidity and the menopause: survey of a gynaecological outpatient clinic. Br J Psychiatry 1977;131:83-9.

[72] Carlson KJ, Miller BA, Fowler FJ, Jr. The Maine Women's Health Study: I. Outcomes of hysterectomy. Obstet Gynecol 1994;83:556-65.

[73] Gath D, Rose N, Bond A, Day A, Garrod A, Hodges S. Hysterectomy and psychiatric disorder: are the levels of psychiatric morbidity falling? Psychol Med 1995;25:277-83.

[74] Ryan MM, Dennerstein L, Pepperell R. Psychological aspects of hysterectomy. A prospective study. Br J Psychiatry 1989;154:516-22.

[75] Duffy LS, Greenberg DB, Younger J, Ferraro MG. Iatrogenic acute estrogen deficiency and psychiatric syndromes in breast cancer patients. Psychosomatics 1999;40:304-38.

[76] Oinonen KA, Mazmanian D. To what extent do oral contraceptives influence mood and affect? J Affect Disord 2002;70:229-40.

[77] Wagner KD. Major depression and anxiety disorders associated with Norplant. J Clin Psychiatry 1996;57:152-7.

[78] Joffe H, Cohen LS, Harlow BL. Impact of oral contraceptive pill use on premenstrual mood: predictors of improvement and deterioration. Am J Obstet Gynecol 2003;189:1523-30.

[79] Smith RN, Studd JW, Zamblera D, Holland EF. A randomised comparison over 8 months of 100 micrograms and 200 micrograms twice weekly doses of transdermal oestradiol in the treatment of severe premenstrual syndrome. Br. J. Obstet. Gynaecol. 1995;102:475-484.

[80] Kroll R, Rapkin AJ. Treatment of premenstrual disorders. J Reprod Med 2006;51:359-70.

[81] Wyatt KM, Dimmock PW, O'Brien PM. Selective serotonin reuptake inhibitors for premenstrual syndrome. Cochrane Database Syst Rev 2002:CD001396. 
[82] Lawrie TA, Herxheimer A, Dalton K. Oestrogens and progestogens for preventing and treating postnatal depression. Cochrane. Database. Syst. Rev. 2000:CD0016.

[83] Gregoire AJ, Kumar R, Everitt B, Henderson AF, Studd JW. Transdermal oestrogen for treatment of severe postnatal depression. Lancet 1996;347:930-3.

[84] Ahokas A, Kaukoranta J, Wahlbeck K, Aito M. Estrogen deficiency in severe postpartum depression: successful treatment with sublingual physiologic 17beta-estradiol: a preliminary study. J Clin Psychiatry 2001;62:332-6.

[85] Soares CN, Poitras JR, Prouty J. Effect of reproductive hormones and selective estrogen receptor modulators on mood during menopause. Drugs Aging 2003;20:85-100.

[86] Soares CN, Joffe H, Cohen LS, Almeida OP. Efficacy of 17beta-estradiol on depression: is estrogen deficiency really necessary? J. Clin. Psychiatry. 2002;63:451-452.

[87] Zweifel JE, O'Brien WH. A meta-analysis of the effect of hormone replacement therapy upon depressed mood. Psychoneuroendocrinology 1997;22:189-212.

[88] Robinson GE. Psychotic and mood disorders associated with the perimenopausal period: epidemiology, aetiology and management. Cns. Drugs. 2001;15:175-184.

[89] Sherman S. Defining the menopausal transition. Am J Med 2005;118:3-7.

[90] Hlatky MA, Boothroyd D, Vittinghoff E, Sharp P, Whooley MA. Quality-of-life and depressive symptoms in postmenopausal women after receiving hormone therapy: results from the Heart and Estrogen/Progestin Replacement Study (HERS) trial. Jama 2002;287:591-597.

[91] Maclennan A, Lester S, Moore V. Oral estrogen replacement therapy versus placebo for hot flushes: a systematic review. Climacteric 2001;4:58-74.

[92] Pearce J, Hawton K, Blake F. Psychological and sexual symptoms associated with the menopause and the effects of hormone replacement therapy. Br J Psychiatry 1995;167:16373.

[93] Burt VK, Altshuler LL, Rasgon N. Depressive symptoms in the perimenopause: prevalence, assessment, and guidelines for treatment. Harv Rev Psychiatry 1998;6:121-32.

[94] Schmidt PJ. Mood, depression, and reproductive hormones in the menopausal transition. Am J Med 2005;118:54-8.

[95] Burnam MA, Wells KB, Leake B, Landsverk J. Development of a brief screening instrument for detecting depressive disorders. Med Care 1988;26:775-89.

[96] Hays J, Ockene JK, Brunner RL, Kotchen JM, Manson JE, Patterson RE, Aragaki AK, Shumaker SA, Brzyski RG, LaCroix AZ, Granek IA, Valanis BG. Effects of estrogen plus progestin on health-related quality of life. N Engl J Med 2003;348:1839-54. 
[97] Tuunainen A, Langer RD, Klauber MR, Kripke DF. Short version of the CES-D (Burnam screen) for depression in reference to the structured psychiatric interview. Psychiatry Res 2001;103:261-70.

[98] Morrison MF, Kallan MJ, Ten Have T, Katz I, Tweedy K, Battistini M. Lack of efficacy of estradiol for depression in postmenopausal women: a randomized, controlled trial. Biol Psychiatry 2004;55:406-12.

[99] Resnick SM, Henderson VW. Hormone therapy and risk of Alzheimer disease: a critical time. Jama 2002;288:2170-2.

[100] Zandi PP, Carlson MC, Plassman BL, Welsh-Bohmer KA, Mayer LS, Steffens DC, Breitner JC. Hormone replacement therapy and incidence of Alzheimer disease in older women: the Cache County Study. Jama 2002;288:2123-2129.

[101] Rymer J, Morris EP. "Extracts from "Clinical evidence": Menopausal symptoms. BMJ 2000;321:1516-1519.

[102] Fitzpatrick LA, Pace C, Wiita B. Comparison of regimens containing oral micronized progesterone or medroxyprogesterone acetate on quality of life in postmenopausal women: a cross-sectional survey. J Womens Health Gend Based Med 2000;9:381-7.

[103] Andreen L, Sundstrom-Poromaa I, Bixo M, Andersson A, Nyberg S, Backstrom T. Relationship between allopregnanolone and negative mood in postmenopausal women taking sequential hormone replacement therapy with vaginal progesterone. Psychoneuroendocrinology 2005;30:212-24.

[104] Sherwin BB. The impact of different doses of estrogen and progestin on mood and sexual behavior in postmenopausal women. J. Clin. Endocrinol. Metab. 1991;72:336-343.

[105] Bjorn I, Bixo M, Nojd KS, Nyberg S, Backstrom T. Negative mood changes during hormone replacement therapy: a comparison between two progestogens. Am J Obstet Gynecol 2000;183:1419-26.

[106] Andreen L, Bixo M, Nyberg S, Sundstrom-Poromaa I, Backstrom T. Progesterone effects during sequential hormone replacement therapy. Eur J Endocrinol 2003;148:571-7.

[107] Whooley MA, Grady D, Cauley JA. Postmenopausal estrogen therapy and depressive symptoms in older women. J Gen Intern Med 2000;15:535-41.

[108] Cathcart CK, Jones SE, Pumroy CS, Peters GN, Knox SM, Cheek JH. Clinical recognition and management of depression in node negative breast cancer patients treated with tamoxifen. Breast. Cancer. Res. Treat. 1993;27:277-281.

[109] Day R, Ganz PA, Costantino JP. Tamoxifen and depression: more evidence from the National Surgical Adjuvant Breast and Bowel Project's Breast Cancer Prevention (P-1) Randomized Study. J. Natl. Cancer. Inst. 2001;93:1615-1623. 
[110] Nickelsen T, Lufkin EG, Riggs BL, Cox DA, Crook TH. Raloxifene hydrochloride, a selective estrogen receptor modulator: safety assessment of effects on cognitive function and mood in postmenopausal women. Psychoneuroendocrinology 1999;24:115-128.

[111] Strickler R, Stovall DW, Merritt D, Shen W, Wong M, Silfen SL. Raloxifene and estrogen effects on quality of life in healthy postmenopausal women: a placebo-controlled randomized trial. Obstet Gynecol 2000;96:359-65.

[112] Jarkova NB, Martenyi F, Masanauskaite D, Walls EL, Smetnik VP, Pavo I. Mood effect of raloxifene in postmenopausal women. Maturitas 2002;42:71-5.

[113] Vessey MP, Fairweather DV, Norman-smith B, Buckley J. A randomized double-blind controlled trial of the value of stilboestrol therapy in pregnancy: long-term follow-up of mothers and their offspring. Br. J. Obstet. Gynaecol. 1983;90:1007-1017.

[114] Fried-Cassorla M, Scholl TO, Borow LD, Strassman HD, Bowers EJ. Depression and diethylstilbestrol exposure in women. J Reprod Med 1987;32:847-50.

[115] Pillard RC, Rosen LR, Meyer-Bahlburg H, Weinrich JD, Feldman JF, Gruen R, Ehrhardt AA. Psychopathology and social functioning in men prenatally exposed to diethylstilbestrol (DES). Psychosom Med 1993;55:485-91.

[116] Titus-Ernstoff L, Perez K, Hatch EE, Troisi R, Palmer JR, Hartge P, Hyer M, Kaufman R, Adam E, Strohsnitter W, Noller K, Pickett KE, Hoover R. Psychosexual characteristics of men and women exposed prenatally to diethylstilbestrol. Epidemiology 2003;14:155-60.

[117] Cole MG, Dendukuri N. Risk factors for depression among elderly community subjects: a systematic review and meta-analysis. Am J Psychiatry 2003;160:1147-56.

[118] Pearlstein TB, Frank E, Rivera-Tovar A, Thoft JS, Jacobs E, Mieczkowski TA. Prevalence of axis I and axis II disorders in women with late luteal phase dysphoric disorder. J Affect Disord 1990;20:129-34.

[119] Chuong CJ, Burgos DM. Medical history in women with premenstrual syndrome. J Psychosom Obstet Gynaecol 1995;16:21-7.

[120] Stowe ZN, Nemeroff CB. Women at risk for postpartum-onset major depression. Am J Obstet Gynecol 1995;173:639-45.

[121] Bloch M, Rotenberg N, Koren D, Klein E. Risk factors associated with the development of postpartum mood disorders. J Affect Disord 2005;88:9-18.

[122] Bloch M, Rotenberg N, Koren D, Klein E. Risk factors for early postpartum depressive symptoms. Gen Hosp Psychiatry 2006;28:3-8.

[123] O'Hara MW, Zekoski EM, Philipps LH, Wright EJ. Controlled prospective study of postpartum mood disorders: comparison of childbearing and nonchildbearing women. $\mathrm{J}$ Abnorm Psychol 1990;99:3-15. 
[124] Nielsen Forman D, Videbech P, Hedegaard M, Dalby Salvig J, Secher NJ. Postpartum depression: identification of women at risk. Bjog 2000;107:1210-7.

[125] Chandraiah S, Richter H, Holley R. Relationship of reproductive cycle-associated and nonreproductive cycle-associated psychological problems in women. Int J Fertil Womens Med 2006;51:33-7.

[126] Garvey MJ, Tuason VB, Lumry AE, Hoffmann NG. Occurrence of depression in the postpartum state. J Affect Disord 1983;5:97-101.

[127] Webster J, Linnane JW, Dibley LM, Pritchard M. Improving antenatal recognition of women at risk for postnatal depression. Aust N Z J Obstet Gynaecol 2000;40:409-12.

[128] Parry BL, Newton RP. Chronobiological basis of female-specific mood disorders. Neuropsychopharmacology 2001;25:S102-S118.

[129] Steiner M. Female-specific mood disorders. Clin Obstet Gynecol 1992;35:599-611.

[130] Novaes C, Almeida OP, de Melo NR. Mental health among perimenopausal women attending a menopause clinic: possible association with premenstrual syndrome? Premenstrual syndrome and psychiatric morbidity at the menopause. Climacteric 1998;1:264-70.

[131] Morse CA, Dudley E, Guthrie J, Dennerstein L. Relationships between premenstrual complaints and perimenopausal experiences. J Psychosom Obstet Gynaecol 1998;19:182-91.

[132] Stewart DE, Boydell KM. Psychologic distress during menopause: associations across the reproductive life cycle. Int J Psychiatry Med 1993;23:157-62.

[133] Richards M, Rubinow DR, Daly RC, Schmidt PJ. Premenstrual symptoms and perimenopausal depression. Am J Psychiatry 2006;163:133-7.

[134] Rubinow DR, Schmidt PJ. The neuroendocrinology of menstrual cycle mood disorders. Annals New York Academy of Sciences 1995;771:648-659.

[135] Tiemeier H, Schuit SC, den Heijer T, van Meurs JB, van Tuijl HR, Hofman A, Breteler MM, Pols HA, Uitterlinden AG. Estrogen receptor alpha gene polymorphisms and anxiety disorder in an elderly population. Mol Psychiatry 2005;10:806-7.

[136] Tsai SJ, Wang YC, Hong CJ, Chiu HJ. Association study of oestrogen receptor alpha gene polymorphism and suicidal behaviours in major depressive disorder. Psychiatr Genet 2003;13:19-22.

[137] Kendler KS, Karkowski LM, Corey LA, Neale MC. Longitudinal population-based twin study of retrospectively reported premenstrual symptoms and lifetime major depression. Am J Psychiatry 1998;155:1234-40.

[138] Steiner M, Dunn E, Born L. Hormones and mood: from menarche to menopause and beyond. J Affect Disord 2003;74:67-83. 
[139] Rubinow DR, Schmidt PJ. Gonadal steroid regulation of mood: The lessons of premenstrual syndrome. Front Neuroendocrinol 2006;27:210-6.

[140] Pardridge WM, Moeller TL, Mietus LJ, Oldendorf WH. Blood-brain barrier transport and brain sequestration of steroid hormones. Am J Physiol 1980;239:E96-102.

[141] Speroff L, Glass R, Kase NG. In Williams CL, Wilkins (eds), Clinical gynecologic endocrinology and infertility. Baltimore, 1994, 59-59.

[142] Facchinetti F, Genazzani AD, Martignoni E, Fioroni L, Nappi G, Genazzani AR. Neuroendocrine changes in luteal function in patients with premenstrual syndrome. J Clin Endocrinol Metab 1993;76:1123-7.

[143] Pike MC, Krailo MD, Henderson BE, Casagrande JT, Hoel DG. 'Hormonal' risk factors, 'breast tissue age' and the age-incidence of breast cancer. Nature 1983;303:767-770.

[144] Rautalahti M, Albanes D, Virtamo J, Palmgren J, Haukka J, Heinonen OP. Lifetime menstrual activity--indicator of breast cancer risk. Eur. J. Epidemiol. 1993;9:17-25.

[145] Pathak DR, Osuch JR, He J. Breast carcinoma etiology: current knowledge and new insights into the effects of reproductive and hormonal risk factors in black and white populations. Cancer 2000;88:1230-1238.

[146] Colditz GA, Frazier AL. Models of breast cancer show that risk is set by events of early life: prevention efforts must shift focus. Cancer. Epidemiol. Biomarkers. Prev. 1995;4:567-571.

[147] Nguyen TV, Jones G, Sambrook PN, White CP, Kelly PJ, Eisman JA. Effects of estrogen exposure and reproductive factors on bone mineral density and osteoporotic fractures. J. Clin. Endocrinol. Metab. 1995;80:2709-2714.

[148] Fox KM, Magaziner J, Sherwin R, Scott JC, Plato CC, Nevitt M, Cummings S. Reproductive correlates of bone mass in elderly women. Study of Osteoporotic Fractures Research Group. J. Bone. Miner. Res. 1993;8:901-908.

[149] Ancelin ML, Ritchie K. Lifelong endocrine fluctuations and related cognitive disorders. Current Pharm Design 2005;11:4229-4252.

[150] Frank E, Rucci P, Katon W, Barrett J, Williams JW, Jr., Oxman T, Sullivan M, Cornell J. Correlates of remission in primary care patients treated for minor depression. Gen Hosp Psychiatry 2002;24:12-9.

[151] Grigoriadis S, Kennedy SH, Bagby RM. A comparison of antidepressant response in younger and older women. J Clin Psychopharmacol 2003;23:405-7.

[152] Pinto-Meza A, Usall J, Serrano-Blanco A, Suarez D, Haro JM. Gender differences in response to antidepressant treatment prescribed in primary care. Does menopause make a difference? J Affect Disord 2006;93:53-60.

[153] Martenyi F, Dossenbach M, Mraz K, Metcalfe S. Gender differences in the efficacy of fluoxetine and maprotiline in depressed patients: a double-blind trial of antidepressants with 
serotonergic or norepinephrinergic reuptake inhibition profile. Eur. Neuropsychopharmacol. 2001;11:227-232.

[154] Kornstein SG, Schatzberg AF, Thase ME, Yonkers KA, Mccullough JP, Keitner GI, Gelenberg AJ, Davis SM, Harrison WM, Keller MB. Gender differences in treatment response to sertraline versus imipramine in chronic depression. Am. J. Psychiatry. 2000;157:1445-1452.

[155] Quitkin FM, Stewart JW, McGrath PJ, Taylor BP, Tisminetzky MS, Petkova E, Chen Y, Ma G, Klein DF. Are there differences between women's and men's antidepressant responses? Am J Psychiatry 2002;159:1848-54.

[156] Cassano P, Soares CN, Cusin C, Mascarini A, Cohen LS, Fava M. Antidepressant response and well-being in pre-, peri- and postmenopausal women with major depressive disorder treated with fluoxetine. Psychother Psychosom 2005;74:362-5.

[157] Shapira B, Oppenheim G, Zohar J, Segal M, Malach D, Belmaker RH. Lack of efficacy of estrogen supplementation to imipramine in resistant female depressives. Biol. Psychiatry. 1985;20:576-579.

[158] Schneider LS, Small GW, Hamilton SH, Bystritsky A, Nemeroff CB, Meyers BS. Estrogen replacement and response to fluoxetine in a multicenter geriatric depression trial. Fluoxetine Collaborative Study Group. Am. J. Geriatr. Psychiatry. 1997;5:97-106.

[159] Schneider LS, Small GW, Clary CM. Estrogen replacement therapy and antidepressant response to sertraline in older depressed women. Am. J. Geriatr. Psychiatry. 2001;9:393399.

[160] Rasgon NL, Altshuler LL, Fairbanks LA, Dunkin JJ, Davtyan C, Elman S, Rapkin AJ. Estrogen replacement therapy in the treatment of major depressive disorder in perimenopausal women. J. Clin. Psychiatry. 2002;63:45-48.

[161] Morgan ML, Cook IA, Rapkin AJ, Leuchter AF. Estrogen augmentation of antidepressants in perimenopausal depression: a pilot study. J Clin Psychiatry 2005;66:774-80.

[162] Amsterdam J, Garcia-Espana F, Fawcett J, Quitkin F, Reimherr F, Rosenbaum J, Beasley C. Fluoxetine efficacy in menopausal women with and without estrogen replacement. J. Affect. Disord. 1999;55:11-17.

[163] Rossouw JE, Anderson GL, Prentice RL, LaCroix AZ, Kooperberg C, Stefanick ML, Jackson RD, Beresford SA, Howard BV, Johnson KC, Kotchen JM, Ockene J. Risks and benefits of estrogen plus progestin in healthy postmenopausal women: principal results From the Women's Health Initiative randomized controlled trial. Jama 2002;288:321-33.

[164] Nelson HD, Humphrey LL, Nygren P, Teutsch SM, Allan JD. Postmenopausal hormone replacement therapy: scientific review. Jama 2002;288:872-81. 
[165] Farquhar CM, Marjoribanks J, Lethaby A, Lamberts Q, Suckling JA. Long term hormone therapy for perimenopausal and postmenopausal women. Cochrane Database Syst Rev 2005:CD004143.

[166] Skouby SO, Al-Azzawi F, Barlow D, Calaf-Alsina Erdogan Ertungealp J, Gompel A, Graziottin A, Hudita D, Pines A, Rozenberg S, Samsioe G, Stevenson JC. Climacteric medicine: European Menopause and Andropause Society (EMAS) 2004/2005 position statements on peri- and postmenopausal hormone replacement therapy. Maturitas 2005;51:814.

[167] Rymer J, Wilson R, Ballard K. Making decisions about hormone replacement therapy. BMJ 2003;326:322-6.

[168] Ettinger B, Barrett-Connor E, Hoq LA, Vader JP, Dubois RW. When is it appropriate to prescribe postmenopausal hormone therapy? Menopause 2006;13:404-10.

[169] Fournier A, Berrino F, Riboli E, Avenel V, Clavel-Chapelon F. Breast cancer risk in relation to different types of hormone replacement therapy in the E3N-EPIC cohort. Int $\mathrm{J}$ Cancer 2005;114:448-54.

[170] Stahl SM. Sex and psychopharmacology: is natural estrogen a psychotropic drug in women? Arch Gen Psychiatry 2001;58:537-8. 
总

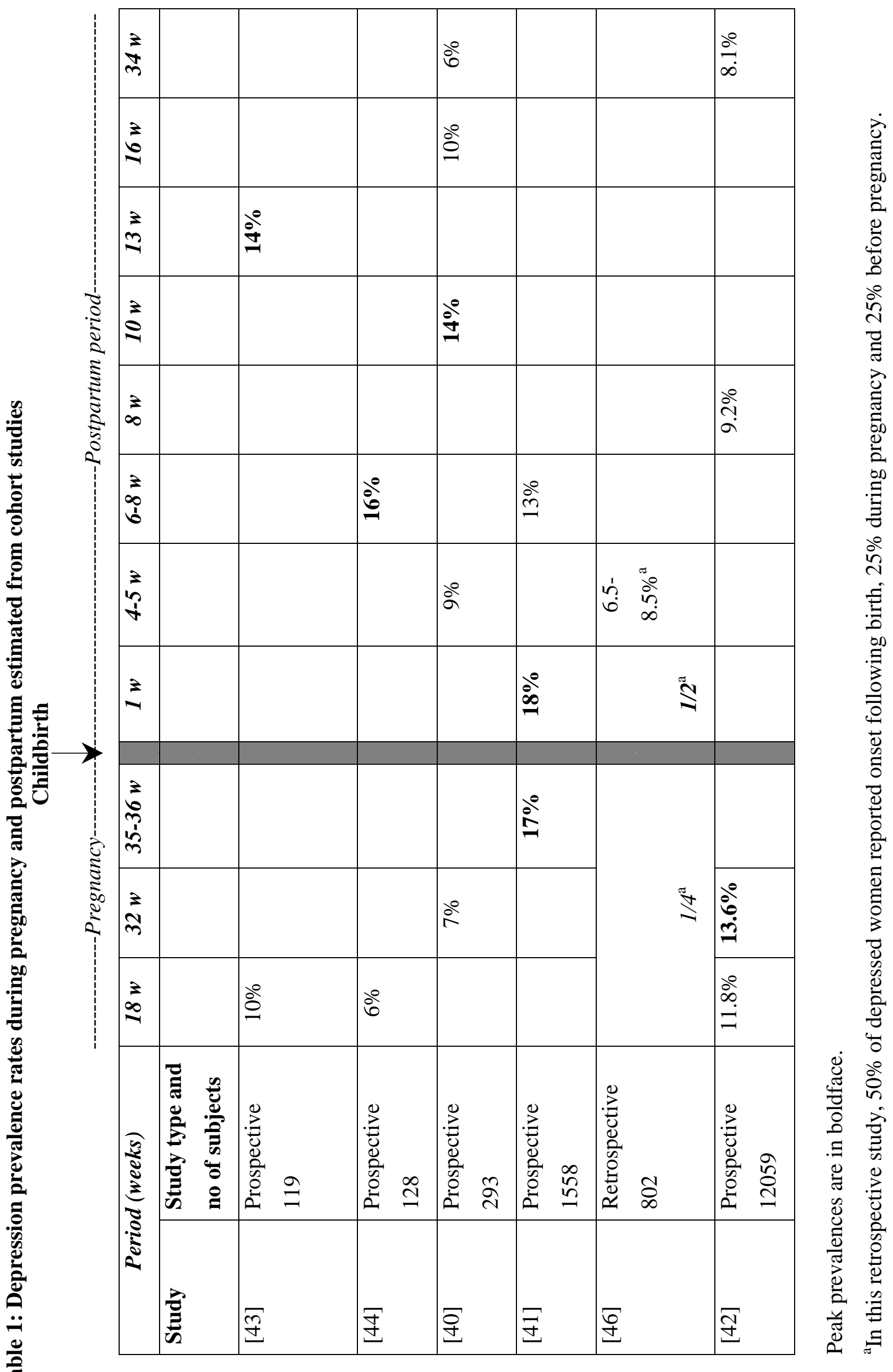


i

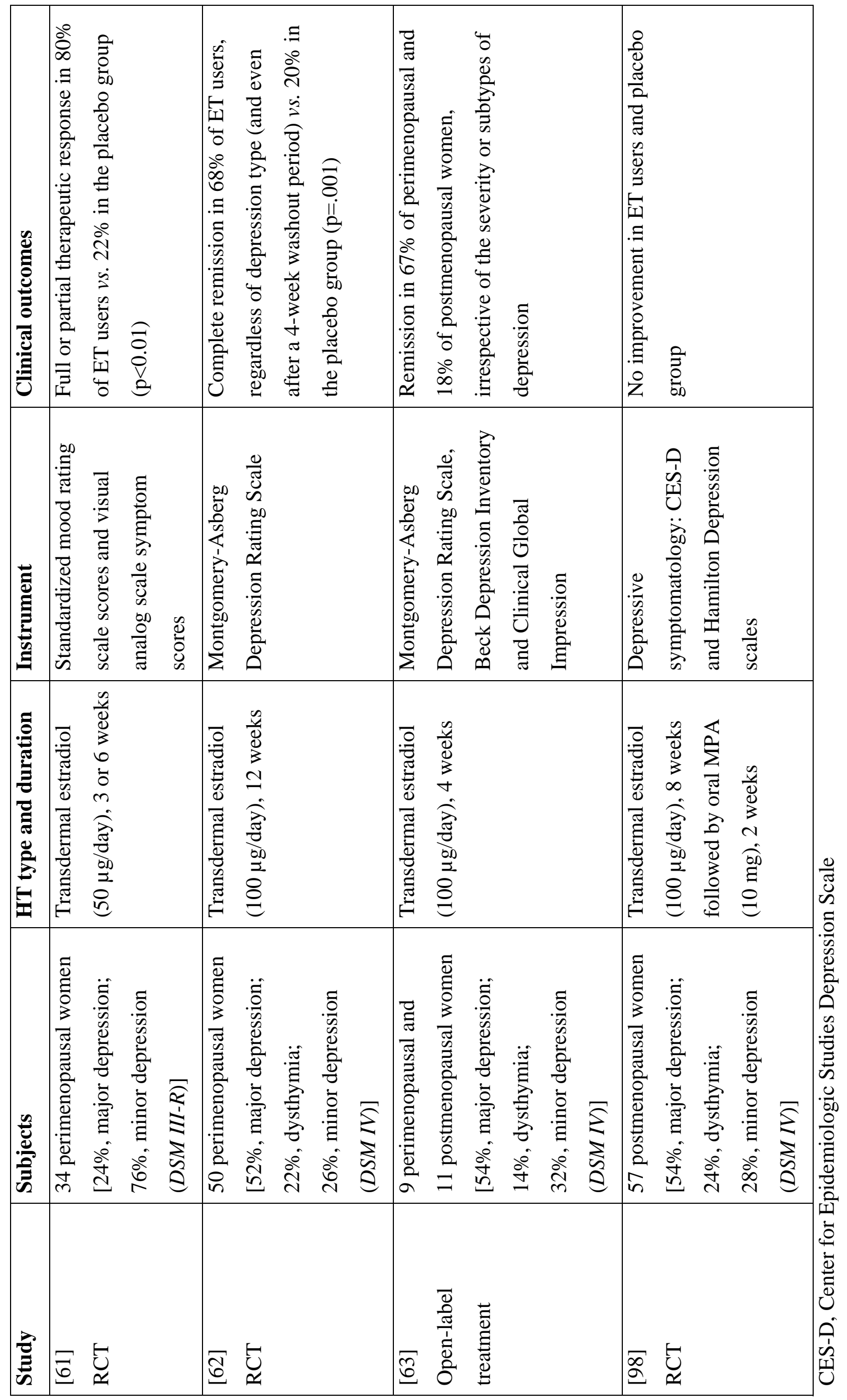

